\title{
Creating Self-Efficacy In Internal Auditors For Information Technology Audits: An On-The-Job Training Perspective
}

Nitaya Wongpinunwatana, Thammasat University, Thailand Patcharamai Panchoo, Kasikornbank, Thailand

\begin{abstract}
The objective of this study is to investigate how to create self-efficacy in internal auditors for information technology (IT) audits. This research conducts a case study to demonstrate that eight constructs affect internal auditor self-efficacy and performance. These constructs are personal factor, behavioral factor, environmental factor, verbal persuasion, emotional arousal, mastery experiences, modeling, and efficacy in an IT audit. This research applies social cognitive and motivational theories and analyzes these theories with the data collected from participants working at two telecommunication and two agricultural companies. The results indicate that the eight constructs affect self-efficacy and trainee performance. A model of creating self-efficacy in IT audit training for internal auditors is proposed from the research findings. Audit managers may consider using the modeling to boost self-efficacy in internal auditors for IT audits.
\end{abstract}

Keywords: Social Cognitive Theory; Self-Efficacy; On-The-Job Training; Information Technology Audit; Internal Auditor

\section{INTRODUCTION}

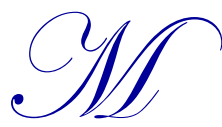

any organizations are expanding their use of automated information technology (IT). As technology is automated and advancing, schemes to commit fraud also advance (Askelson et al., 2009). Internal auditors are expected to take a role in helping organizations manage fraud risks by ensuring that appropriate controls are in place to help prevent and detect fraud. Today, many internal audit departments are faced with tight budgets, limited staffing, and extended workloads (Askelson et al., 2009). To meet the expectations of management, business owners, and boards of directors, audit managers are challenged to use available resources effectively and efficiently. The internal audit department may have to cultivate staff skill sets through professional development. Internal auditors require appropriate skills and should use available technological tools to help them maintain successful fraud management that covers prevention, detection, and investigation (Askelson et al., 2009). In addition, internal auditors must have sufficient knowledge to evaluate the risk of fraud information technology. Therefore, an audit department faces challenges on how to train its internal auditors to keep pace with information technology auditing knowledge. Organizations increasingly recognize that formal training is critical not only to the success of internal auditors' safeguard work, but also to the organizations' competitive position in the marketplace (Devaraj \& Babu, 2004). One strategy is to deliver effective training programs to internal auditors. In order to align training with departmental needs, audit managers must understand appropriate types of high-quality training. Moreover, the initial interview with internal auditors indicates that they do not have self-efficacy in auditing IT, even though they have previous experience. They did not even know whether they had conducted their IT audits accurately.

Training involves improving the skills, knowledge, and attitudes of employees so they become more efficient and productive (Dineshbakshi, 2013). Types of training consist of on-the-job and off-the-job training. Onthe-job training is done by watching a skilled employee doing the job. This more experienced employee passes his/her expertise to another employee. Thus, employees are performing their regular work while they learn. This 
training is usually conducted for operational level employees. On-the-job training is suitable for unskilled and semiskilled jobs. Research has shown that employees who have undergone this training enjoy and respond better to this method because of their familiarity with the surroundings (Milkround, 2013; Vuran \& OlÇay gÜl, 2012). On-the-job training has three incentives: 1) the favorable relationship between training costs and benefits, 2) the possibility to train just-in-time, and 3) what was learned from the employee's own work situation (Klink \& Streumer, 2002).

Off-the-job training is whereby an employee receives when going away from the workplace to attend a classroom, seminar, or workshop. The objective of off-the-job training is to prepare trainees to have fundamental knowledge for on-the-job training. Although trainers are qualified in their area of expertise, the content of the training may not be directly relevant to an employee's work situation. This training is normally employed at the managerial level to provide fundamental concepts of new knowledge.

The two most frequently used methods of training are on-the-job and classroom. However, little research exists as to the effectiveness of these two training methods (Taylor, 2013). The success of training to develop employee skills depends on the effective and proper use of appropriate training methods (Vuran \& OlÇay gÜl, 2012).

The research questions of this study are 1) What is the suitable training method to promote self-efficacy in internal auditors for IT audits? and 2) What are the relevant factors needed to consider for the training to enhance self-efficacy in internal auditors for IT audits?

This study differs from other employee training research in that its specific focus is on the effectiveness of IT audit training. This study also aims to determine methods to train internal auditors who already possess fundamental knowledge in IT but presently work as financial auditors to become IT auditors. Moreover, the selfefficient construct has been considered in the context of IT audits.

\section{THEORETICAL BACKGROUND}

In the existing literature, there are many studies on the effects of training on learner performance. This study adopts two theories (social cognitive theory and motivation) which may impact auditor learning and behavior in IT audits.

Social cognitive theory has been broadly studied in the fields of social science, education, and information application (Hung et al., 2011). This theory has been discussed as the core concept of many constructs such as modeling and skill training (Compeau et al., 1999; Piccoli et al., 2000; Hsu \& Chiu, 2005; Hung et al., 2011). Modeling is defined as copying or imitating another person's actions (McCormick \& Martinko, 2004; Ratten \& Ratten, 2007). Social cognitive theory provides a framework for understanding and predicting human behavior. The theory posits that human behavior is influenced by the interaction of personal, behavioral, and environmental factors (Bandura, 1986; Bandura, 1997). The personal factors include cognition, affective, and biological events. Behavioral factors refer to one's response to the environment. They include the way one acts based on different factors, such as motivation and attitude. Environmental factors are composed of workplace environment and conditions, such as available budget and time for training. In addition, Bandura (1997) identified three key processes within the personal factors: (a) self-efficacy beliefs, (b) outcome expectations, and (c) self-regulated learning (Erlich, 2011). Selfefficacy is a major component of Bandura's social-cognitive theory (Harrison et al., 1997). Outcome expectations are the anticipated consequences a learner expects from engaging in a chosen behavior (Erlich, 2011). Self-regulated learning refers to the process of learners taking control and responsibility for their learning (Erlich, 2011). Both outcome expectations and self-efficacy beliefs lead to action, performance, and outcomes (Bandura, 1997). Outcome expectations constitute cognitive, emotional, and motivational variables.

The interaction between personal and behavioral factors influences a person's thoughts and actions and the interaction between personal and environmental factors influences human beliefs and cognitive competencies, which include individual capability, knowledge, and skills. The interaction between environmental and behavioral factors modifies human behavior. These three factors also may influence each other. In training, the theory posits that the trainee's way of thinking (personal factors such as cognition) and environmental factors (such as workplace 
environment) can change one's behavior. In other words, trainees learn by observing what others (trainers), who are role models, do and will not do. The trainees then reproduce the same actions. Meanwhile, this theory refers not only to observing behavior but also to receiving instruction and guidance of how to complete a behavior (Bandura, 1997).

Self-efficacy is the outcome expectancy of training that an individual believes will happen from doing a certain action (Bandura, 1986). Learning from other people's behavior is a central idea of social cognitive theory and self-efficacy (Bandura, 1986; Bandura, 1997). Social modeling is one of the means to increase self-efficacy. Self-efficacy has also been used to predict behavior in various situations (Bandura, 1997). In addition, observational learning (vicarious experiences), verbal persuasion, enactive mastery, and emotional arousal influence an individual's self-efficacy beliefs (Bandura, 1986; Zimmerman \& Cleary, 2006; Erlich, 2011). Therefore, selfefficacy will be increased through managers' verbal persuasion which is aimed at encouraging trainees to attend training program (Gist, 1987).

Self-efficacy refers to a person's belief in his/her ability to do a particular task (Mitchell et al., 1994). Selfefficacy can be classified into that of general information systems and task-specific information systems (Devaraj \& Babu, 2004). General information systems self-efficacy is the internal auditor's judgment of efficacy across multiple information systems domains. Task-specific information systems self-efficacy is one's perceptions of ability to perform information systems auditing tasks. Much research in auditing has focused on auditor self-efficacy. However, the self-efficacy construct has seldom been tested in the context of IT audits.

Behavior of trainees may be changed depending on whether they are rewarded or punished, which is motivation. Motivation has been defined as an internal state, need, or desire that energizes and directs behavior (Gears, 2012). Motivation is generally classified as intrinsic or extrinsic (Gears, 2012). Intrinsic motivation is a move to do something for the sake of the activity itself and extrinsic motivation is pressure, rewards, or threats of punishment in order to get something. Intrinsic motivation has a mediation effect on the relationship between extrinsic motivation and student performance (Mo, 2011). In addition, self-efficacy beliefs and outcome expectations affect the motivational beliefs leading to performance (Tai, 2006; Erlich, 2011).

\section{COMPREHENSIVE MODEL}

Figure 1 outlines the chronological sequence of the decision process to select effective IT audit training. The decision process includes four phases: 1) search for and compare training methods, 2) create a process for the selected training, 3) launch the selected training process, and 4) evaluate the performance of the training. Social cognitive theory is used in Phases 1, 3, and 4, while motivation theory is used in Phase 2. In these phases, a manager considers multiple factors encompassing eight related variables - personal factor, behavioral factor, environmental factor, verbal persuasion, emotional arousal, mastery experiences, modeling, and efficacy in IT audit.

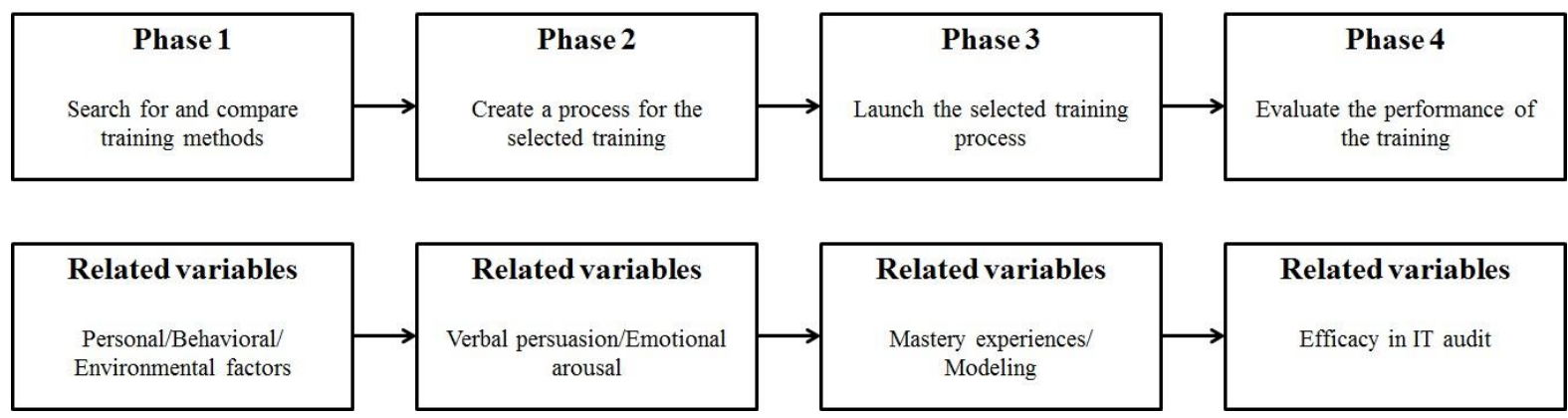

Figure 1: Model of the Decision Process to Select Effective IT Audit Training

The explanation of each phase is as follows:

Phase 1 is searching for and comparing training methods - the starting point of training. During this phase, an audit manager will select suitable training methods for IT auditing from various training methods (i.e., off-the-job and on-the-job training). During the search, an audit manager will consider training methods which are suitable for 
the characteristics of the organization's internal audit staff and for the organization's environment, with the aim of developing appropriate behavior and skill sets. Therefore, this study posits that an audit manager will consider three factors from social cognitive theory (personal, behavioral, and environmental factors) in searching for an effective training method.

Phase 2 is creating a process for the selected training. Apart from adjusting the training style to make it consistent with an IT audit (i.e., training content, objective and goal of training, and training processes), the audit manager has to determine suitable motivational factors. Motivations can be intrinsic and extrinsic, as stated by Bandura (1986, 1997). Therefore, this research posits that a manager will consider using intrinsic motivations verbal persuasion and emotional arousal - to motivate trainees.

Phase 3 is launching the selected training process. During a practice IT audit, trainees will observe how to conduct an IT audit from an experienced role model. They also will practice how to audit in a real-world situation under close supervision from the model. Observation and practice will encourage trainees to adjust their behavior by imitating the model's behavior. An audit manager will introduce IT auditing mastery experiences in this phase.

Phase 4 is evaluating the performance of the training. After completing the training, the audit manager will evaluate the effectiveness of training on trainee performance. This is done by measuring trainee efficacy in IT audits.

\section{RESEARCH METHOD}

To investigate the study questions noted above, research based on a multi-case research design was used to collect data. The multi-case design is the most sophisticated of the four case designs discussed by Yin (Spicer, 1995). This case research design was chosen because it is appropriate in understanding the process of selecting training methods as well as understanding the effectiveness of applying the training to IT auditors.

This research is targeted at large firms because they have the resources to implement sophisticated information technologies which need to be safeguarded from fraud. Research was carried out at four multinational firms in Thailand (two telecommunication and two agricultural companies). In this study, two groups of participants working at the two telecommunication companies were involved. The first group consisted of two chief audit executives and the participants in the second group were four information technology audit specialists. Twelve internal audit chiefs, working at the two agricultural companies, also participated. The participants in each firm possessed work experience in their current position of at least five years. The in-depth interviews were conducted by researchers in the participants' offices without any interrupting telephone calls, colleagues, or other disturbances. Each interview lasted approximately 30-90 minutes and they followed the same pre-determined structure and predefined questionnaire. Each interview commenced with the researchers stating that the revealed insights and collected data were completely confidential and anonymous and any quotes used would not be attributed to any specific participants. The content in the recorded interviews was transcribed and saved as a written manuscript (approximately 80 pages) in order to be qualitatively analyzed by the researchers.

\section{ANALYSIS AND INTERPRETATION}

The data collected from the four multinational firms were analyzed and interpreted within the context of eight factors related to each phase in the decision process - personal factor, behavioral factor, environmental factor, verbal persuasion, emotional arousal factor, mastery experiences, modeling, and efficacy in IT audit. For data from each participant, the analysis concentrates on whether the data are consistent with the explanation of these eight factors. If findings obtained from subsequent participants also were consistent with the above eight factors, it was concluded that the viability of the factors was strengthened. Thus, if the pattern observed in the second participant was similar to the pattern observed in the first participant, it was interpreted as a replication. If the patterns were not similar, the researchers tried to understand why the patterns observed did not match those factors. The following sections present the analysis and interpretation for these eight factors. 


\section{Description of Data}

\section{Personal, Behavioral, and Environmental Factors}

As stated above, this research examines social cognitive theory in terms of personal, behavioral, and environmental factors. The analysis of data is used to answer the research questions whether 1) audit mangers consider personal, behavioral, and environmental factors in selecting suitable training methods and 2) on-the-job training is a suitable training method to promote self-efficacy in internal auditors for IT audits.

The results reveal that $78 \%$ of participants agree in considering three factors (personal, behavioral, and environmental factors) in searching for and comparing suitable training methods (Phase 1). For the personal factor, the participants agree that trainees in IT auditing should have a fundamental knowledge in information technology such as risk assessment in IT, IT security, network, network operating system, database and web application security (i.e., OWASP). In addition, they should have knowledge in business processes. These results are consistent with Parker (2010). All participants expect that the outcome of training (outcome expectancy) is the learner's knowledge and ability to perform IT auditing work. For the environmental factor, the participants also consider budget and time used in training IT auditors. Participants made the following statements:

"To train IT audit staffs effectively and efficiently, an IT audit manager should allocate sufficient training budget. The manager should define a training plan for IT audit staff every year. However, with limited staffing and extended workloads, the audit department also needs to consider time used for training. Attending training may affect IT auditors' normal workload. Therefore, an IT audit manager should consider time for training carefully. The manager has to prepare a detailed timetable for audit staff work tasks together with training time."

"A sufficient budget is one of the factors necessary for IT audit training. The audit department is expected to take a proactive role in helping organizations manage fraud risks by ensuring that appropriate controls are in place to help prevent and detect fraud, thus IT auditors have substantial workloads. Auditors may not have enough time to attend formal training."

For the behavioral factor, the participants agree that if IT auditors have an opportunity to be involved in a real IT audit, they will gain experience which, in turn, will affect auditor skills in an IT audit.

In summary, personal, behavioral, and environmental are the major factors used in searching for and comparing training methods. These factors are the components of social cognitive theory which is based on the idea that observing other people's behavior can change a person's way of thinking (cognition). Moreover, this observation also can change personal factors, thereby affecting a person's behavior. On-the-job training - observing what others do - enhances trainee learning, making it one of the most suitable training methods for IT auditing. All audit managers agree that training their staffs by using on-the-job training is appropriate.

\section{Verbal Persuasion and Emotional Arousal Factor}

This research examines the motivation theory in terms of verbal persuasion and emotional arousal factor. The analysis of data is used to answer the research question whether audit mangers consider using verbal persuasion and emotional arousal factor to motivate internal auditors so that they will actively participate in the selected training.

The results reveal that $80 \%$ of participants agree in considering two factors - verbal persuasion and emotional arousal factor - in creating the process for the selected training method (Phase 2). Some audit managers indicated that on-the-job training should incorporate clear objectives, goals, content and communication to internal audit staffs so that they will be able to prepare themselves sufficiently for the training. On-the-job training content should include scope of training, priority of tasks to be trained in, pre-requisite skills of trainees, who will be trained, time span of training, and training tools and techniques. 
As the available audit staff already may be familiar with traditional auditing and therefore opposed to this IT audit training, the audit department may have to provide persuasion and emotional arousal. The managers will have to arouse auditor participation by increasing motivation. Participants made the following statements:

"The communication to trainees of objectives and benefits will create efficient and effective training results."

"The trainees learn and practice by watching what others do, with the goal of building proficiency. Under the instruction of trainers, trainees will be able to correctly perform an IT audit."

"If trainees receive feedback and errors in their understanding are corrected immediately by the trainers, the trainees receive positive encouragement and the training will be successful."

In summary, the research found that verbal persuasion and emotional arousal factor are important determinants of effective and efficient training process setting. Managers have to clearly communicate the objectives, goals, and content of on-the-job training to audit staff.

\section{Mastery Experiences and Modeling}

This research examines the self-efficacy construct in terms of mastery experiences and modeling. The analysis of data to answer the research question whether mastery experiences and modeling promotes internal auditor self-efficacy in IT auditing is as follows:

The results reveal that $83 \%$ of participants agree in considering two factors - mastery experience and modeling - in launching the selected training process (Phase 3). Some managers indicated that audit managers should have senior auditors with IT auditing experience as trainers. They should act as IT audit role models and demonstrate how to conduct IT audits. These trainers must provide clear IT auditing steps and detailed instructions, arrange task levels from easy to difficult, and frequently review tasks assigned to trainees. The trainers also have to evaluate trainee performance. The training should include tools to be used in each step. Modeling will enhance trainees' knowledge of IT auditing because trainees will be able to observe auditing processes closely. These observations provide learning that cannot be done with other training methods, while some tasks are better learned by observation than by explanation. Observation can produce detailed records of what modeling actually does during an audit. In addition, many types of data can be obtained more accurately through observation than by questioning. Once trainees follow modeling to perform a task step-by-step, they should be able to finish the task. The trainees will gain experience and mastery of an IT audit. Participants made the following statements.

"IT audit modeling will enhance the understanding of how to conduct IT auditing. On-the-job training is similar to having a mentor provide guidance to the trainee. If the trainee encounters problems, he/she will be able to solve problems via suggestions learned from the role model. This training method is suitable for training operating staff."

"On-the-job training takes more time than other training methods. Also, it may not be suitable for training a large number of staff."

In summary, observational learning or vicarious experience from a proficient role model builds the learner's knowledge and understanding. During on-the-job training, learners observe the IT auditing model verbally and visually, explaining how to conduct an IT audit.

\section{Efficacy in IT Audits}

This research evaluates trainee performance in IT auditing by measuring self-efficacy. Measurements best to use in determining the effectiveness and efficiency of the selected training are explained in this section.

The results reveal that $78 \%$ of participants agree in considering self-efficacy in evaluating the performance of IT audit training (Phase 4). Some participants use the ability to correctly complete a task, which is similar to those done during on-the-job training in evaluating the trainees' performance. In addition to the ability to complete a task 
without supervision, other measurements of efficiency and effectiveness of training include the ability to analyze and solve problems and set an audit plan. All participants agree that if trainees can provide auditing consultation to other colleagues, they possess self-efficacy. Participants made the following statements:

"If trainee supervisors and colleagues accept their skills, trainees possess self-efficacy. In addition, the ability to fulfill assigned tasks also indicates trainee self-efficacy."

"Normally, trainees who attended on-the-job training will possess self-efficacy and be able to express and transfer their knowledge to other colleagues, including their supervisor."

In summary, most participants agree that efficacy in IT audits can be used to evaluate training performance at the end of the training. In addition, learners can increase their self-efficacy with on-the-job training.

\section{CONCLUSION AND SUGGESTIONS FOR FUTURE RESEARCH}

There are many factors that affect auditor self-efficacy for IT audits, including personal factor, behavioral factor, environmental factor, verbal persuasion, emotional arousal factor, mastery experiences, and modeling. The contributions of this research are twofold. First, understanding each factor in detail may assist IT audit managers in selecting an appropriate training method. In addition, management can use these factors to promote efficient and effective training for IT audit staffs. Second, by understanding these factors, training departments within an organization can provide training that meets trainee needs.

Based on results from both in-depth interviews and prior research (i.e., Bandura, 1986, 1997; Ratten \& Ratten, 2007; Erlich, 2011; Mo, 2011), the authors propose factors that affect the self-efficacy and performance in IT auditing, as shown in Figure 2. The modified model consists of the original constructs of social cognitive theory (modeling, outcome expectancy, and self-efficacy) with the addition of motivation and performance. The model posits that modeling and outcome expectancy affect performance via self-efficacy. Meanwhile, motivation moderates the relationship among modeling, outcome expectancy and self-efficacy.

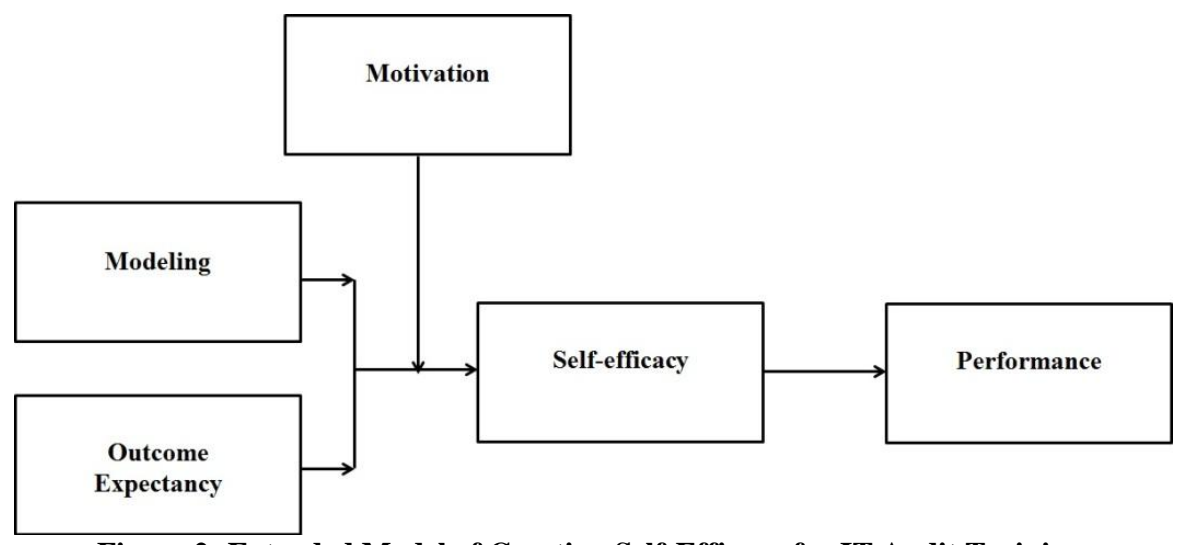

Figure 2: Extended Model of Creating Self-Efficacy for IT Audit Training

The limitation of this particular research is sample size. The sample size of 16 auditors may not be representative of the population as a whole. However, this research could show trends that will be useful for determining suitable training methods. Another limitation is that participants include both experienced and inexperienced IT auditors. The inexperienced auditors, because of lack of experience, may not have provided responses relevant to the study.

This research was conducted to determine the factors affecting self-efficacy, in general, but does not provide a detailed analysis of those factors. One area of future research could therefore look further into the factors to see if there are any other factors influencing IT auditor self-efficacy. The factors in this research are based on previous research which might not cover all the relevant self-efficacy factors. Future studies could therefore look at 
other factors that are not included in this research, such as outcome values suggested by Ratten and Ratten (2007). In addition, research could be done using different methodologies in order to replicate the results. This research uses a multi-case study approach with in-depth interviews. Future research could use a questionnaire with a larger sample size for a more accurate representation of the whole population. In addition, other factors creating self-efficacy from training methods, such as learning by teaching, could be studied.

\section{AUTHOR INFORMATION}

Nitaya Wongpinunwatana is an Associate Professor in the Department of Management Information Systems at Thammasat Business School, Thammasat University. She earned her Ph.D. in the field of information systems from the University of Queensland in Australia. She is interested in conducting research in teaching and learning on information systems audit, computer security, and enterprise resource planning. E-mail: wongpinn@tu.ac.th (Corresponding author)

Patcharamai Panchoo is a relationship manager at Kasikornbank and she earned her bachelor in Accounting at Kasetsart University and earned her Master's degree at Thammasat Business School, Thammasat University. Before joining the bank, she worked in Charoen Pokphand Foods (CPF) Group as an internal auditor. Her research interests include accounting and auditing.

\section{REFERENCES}

1. Askelson, K., Lanza, R., Millar, P., \& Prosch, M. (2009). Global technology audit guide (GTAG) 13: Fraud prevention and detection in an automated world. USA: The Institute of Internal Auditors.

2. Bandura, A. (1986). Social foundations of thought and action: A social cognitive theory. Englewood Cliffs, NJ: Prentice Hall.

3. Bandura, A. (1997). Self-efficacy: The exercise of control. New York: W. H. Freeman.

4. Compeau, D. R., Higgins, C. A., \& Huff, S. (1999). Social cognitive theory and individual reactions to computing technology: A longitudinal study. MIS Quarterly, 23(2), 145-158.

5. Devaraj, S., \& Babu, S. R. (2004). How to measure the relationship between training and job performance. Communication of the ACM, 47(5), 63-65.

6. Dineshbakshi. (2013). Types of training and its objective. Retrieved from http://www.dineshbakshi.com/ igcse-business-studies/people-at-work/revision-notes/851-typess-of-training-and-its-objective.

7. Erlich, R. (2011). Developing self-efficacy and self-regulated learning in academic planning: applying social cognitive theory in academic advising to assess student learning outcomes. (Unpublished doctoral dissertation). Oregon State University.

8. Gears, D. A. (2012). Corporate wikis underground: An investigation of motivation and collaborative engagement. Journal of Management and Marketing Research, 1-20.

9. Gist, M. E. (1987). Self-efficacy: Implications for organizational behavior and human resource management. Academy of Management Review, 12, 472-85.

10. Harrison, A. W., Rainer, R. K. Jr., Hochwarter, W. A., \& Thompson, K. R. (1997). Testing the selfefficacy-performance linkage of social-cognitive theory. The Journal of Social Psychology, Feb, 137(1), 79-87.

11. Hsu, M. H., \& Chiu, C. M. (2005). Internet self-efficacy and electronic service acceptance. Decision Support Systems, 38(3), 369-381.

12. Hung, W., Chang, L., Yen, D. C., Ho, C. \& Chiang, M. (2011). ERP success in the SMEs: The perspectives of service quality and social cognitive theory. Asia Pacific Management Review, 16(4), 503-519.

13. Klink, M. R. V. D., \& Streumer, J. N. (2002). Effectiveness of on-the-job training. Journal of European Industrial Training, 26(2), 196-199.

14. McCormick, M. J., \& Martinko, M. J. (2004). Identifying leader social cognitions: integrating the causal reasoning perspective into social cognitive theory. Journal of Leadership and Organizational Studies, $10(4), 2-11$.

15. Milkround. (2013). Types of training. Retrieved from http://www.milkround.com/career-advice/careertips/in-the-workplace/types-of-training/ 
16. Mitchell, T. R., Hopper, H., Daniels, D., George-Falvy, J., \& James, L. R. (1994). Predicting self-efficacy and performance during skill acquisition. Journal of Applied Psychology, 79, 506-517.

17. Mo, S. (2011). An exploratory study of intrinsic \& extrinsic motivators and student performance in an auditing course. American Journal of Business Education, February, 19-25.

18. Parker, R. G. (2010). Business skills for the IT audit and assurance professional. ISACA Journal, 3, 1-8.

19. Piccoli, G., Ahmad, R., \& Ives, B. (2001). Web-based virtual learning environments: A research framework and a preliminary assessment of effectiveness in basic IT skills training. MIS Quarterly, 25(4), 401-426.

20. Ratten, V., \& Ratten, H. (2007). Social cognitive theory in technological innovations. European Journal of Innovation Management, 10(1), 90-108.

21. Spicer, B. (1995). A multi-case investigation of a theory of the transfer pricing process. Workshop, Department of Commerce.

22. Taylor, M. (2013). Six types of training and development techniques. Retrieved from http://ezinearticles.com/?Six-Types-of-Training-and-Development-Techniques\&id=1944536

23. Tai, W. (2006). Effects of training framing, general self-efficacy and training motivation on trainees' training effectiveness. Personnel Review, 35(1), 51-65.

24. Vuran, S., \& OlÇay gÜl, S. (2012). On-the-job training of special education staff: Teaching the simultaneous prompting strategies. Educational Sciences: Theory \& Practice, 12(3), 2101-2110.

25. Zimmerman, B. J., \& Cleary, T. J. (2006). Adolescents' development of personal agency: The role of selfefficacy beliefs and self-regulatory skill. In F. Pajares \& T. C. Urdan (Eds.), Self-efficacy beliefs of adolescents: A volume in adolescence and education. (pp. 45-69). Greenwich, CT: Information Age. 
\begin{tabular}{ll} 
International Journal of Management \& Information Systems - Third Quarter $2014 \quad$ Volume 18, Number 3 \\
\hline
\end{tabular}

NOTES 